\title{
Group B streptococcal necrotizing fasciitis from a decubitus ulcer
}

\author{
Brian T. Kloss • Claire E. Broton • Elliot Rodriguez
}

Received: 8 June 2010 /Accepted: 6 September 2010 / Published online: 3 November 2010

(C) The Author(s) 2010. This article is published with open access at Springerlink.com

\begin{abstract}
A 29-year-old man with paraplegia secondary to a gunshot wound presented to the emergency department (ED) with worsening abdominal pain over the past 2 weeks with associated fever, dysuria, nausea, and vomiting. He had been diagnosed with a urinary tract infection (UTI) 2 days earlier and was started on antibiotics without improvement.

On examination he was afebrile, tachycardic up to 140 , tachypneic, and diaphoretic. His abdomen was rigid and diffusely tender to palpation with hypoactive bowel sounds. He had a mildly tender $3 \times 3 \mathrm{~cm}$ decubitus ulcer on his buttocks. His WBC was elevated at 18 , with an absolute neutrophil count of 11.09 and 3.17 bands. The creatine kinase was elevated at 1,001 and a serum lactate level was 8.7. Abdominal computed tomography (CT) showed free air dissecting into the retroperitoneal and peritoneal fascial planes consistent with necrotizing fasciitis (Fig. 1, Fig. 2, Fig. 3, and Fig. 4).
\end{abstract}

The patient was taken for emergent exploratory laparotomy and extensive debridement. Throughout his hospital course he returned to the operating room (OR) a total of 11

B. T. Kloss $(\square) \cdot$ C. E. Broton $\cdot$ E. Rodriguez

Department of Emergency Medicine, Upstate Medical University, 550 East Genesee Street,

Syracuse, NY 13202, USA

e-mail: klossb@upstate.edu

C. E. Broton

e-mail: brotonc@upstate.edu

E. Rodriguez

e-mail: rodrigue@upstate.edu times for further debridement and repair of complications, which included a perforated cecum and a colocutaneous fistula. Cultures from the wound grew Prevotella bivia and group B streptococci, while cultures of the peritoneal tissue grew only group B streptococci. Neither blood nor urine cultures grew any bacteria. In addition to his numerous surgeries he was treated with IV clindamycin and piperacillin/tazobactam. After 10 weeks of hospitalization he was transferred to a rehab facility.

Necrotizing fasciitis, more commonly known as the "flesh-eating disease," is an aggressive and highly destructive infection of fascia and muscle with a high morbidity and mortality. Necrotizing fasciitis from decubitus ulcers is rare, with only a few reported cases $[1,2]$. The diagnosis can be difficult, as symptoms are nonspecific and the initial skin lesions are often benign compared to the underlying tissue destruction [3]. A high

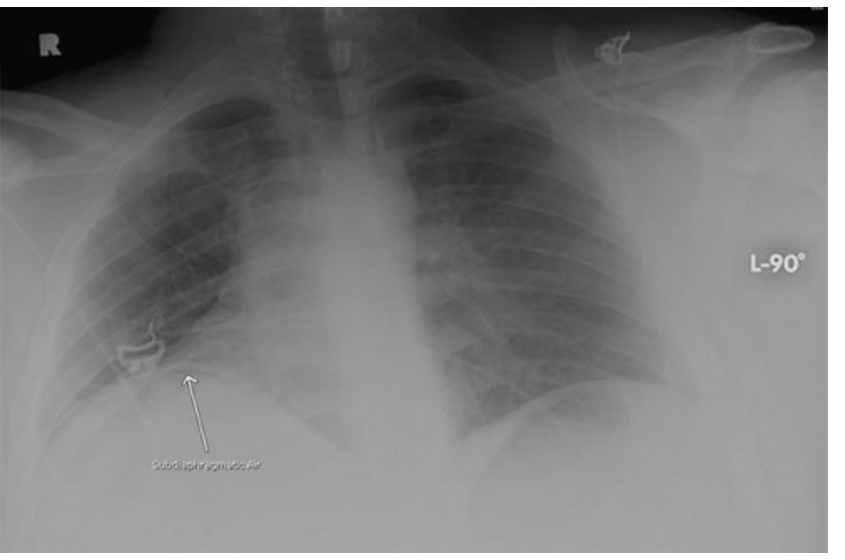

Fig. 1 Chest X-ray showing subdiaphragmatic free air 


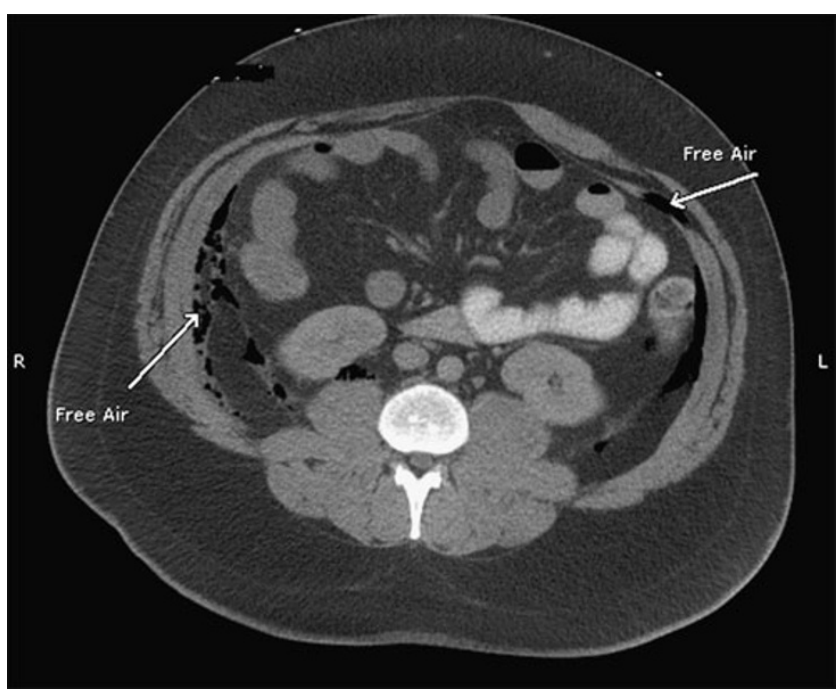

Fig. 2 CT scan through the abdomen showing free air

index of suspicion should be present when abdominal radiographs demonstrate subcutaneous emphysema in a patient with skin lesions [4]. On CT, free air with evidence of soft tissue invasion is consistent with the diagnosis [2]. This case is unique because the decubitus ulcer and

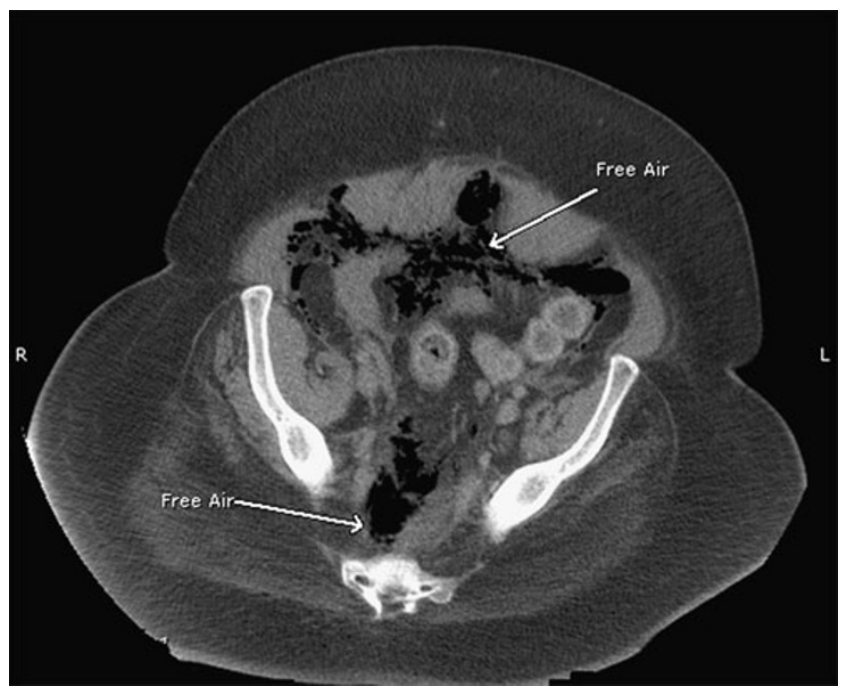

Fig. 3 CT scan through the pelvis showing free air

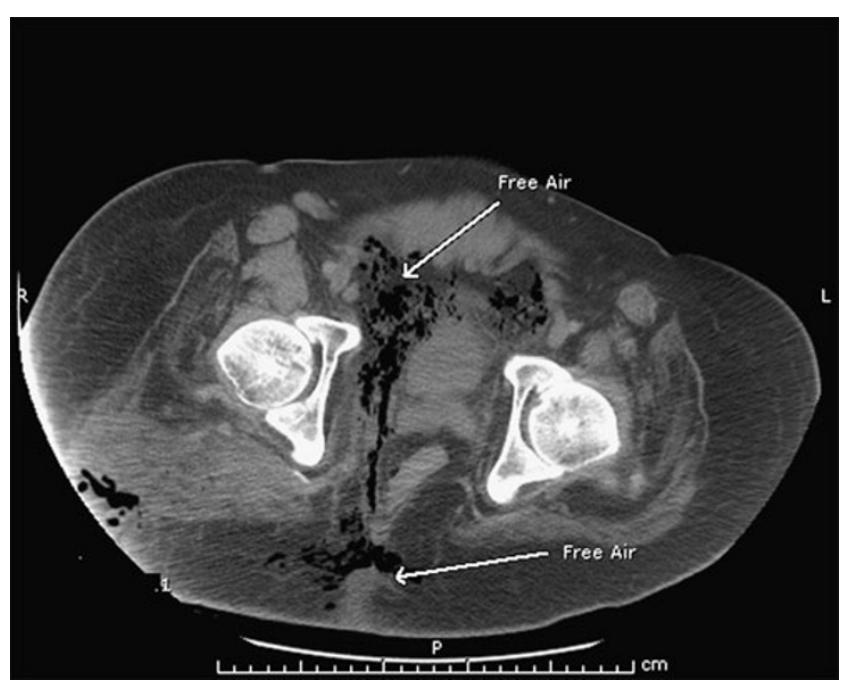

Fig. 4 CT scan through the lower pelvis showing air tracking

peritoneal samplings both grew and isolated group B streptococci as the causative agents; necrotizing fasciitis is typically caused by group A streptococci, Staphylococcus aureus, Vibrio vulnificus, Clostridium perfringens, Bacteroides fragilis, or mixed flora.

Open Access This article is distributed under the terms of the Creative Commons Attribution Noncommercial License which permits any noncommercial use, distribution, and reproduction in any medium, provided the original author(s) and source are credited.

\section{References}

1. Kaplan LJ, Pameijer C, Blank-Reid C et al (1998) Necrotizing fasciitis: an uncommon consequence of pressure ulceration. Adv Wound Care 11:185-189

2. Cunningham SC, Napolitano LM (2004) Necrotizing soft tissue infection from decubitus ulcer after spinal cord injury. Spine 29(8): E172-E174

3. Olsen RJ, Musser JM (2010) Molecular pathogenesis of necrotizing fasciitis. Annu Rev Pathol 5:1-31

4. Miller G, MacLean AA, Hiotis K (2008) Surgical images: soft tissue. Necrotizing fasciitis of the abdominal wall. Can J Surg 51 (1):56 